\title{
The new rules of naturopathy
}

A lberta has become the fifth province in Canada to regulate naturopathic doctors, following a push by the profession to ensure consistent regulations and practice standards across the country.

The province established the College of Naturopathic Doctors of Alberta at the end of July, through a new regulation that came into effect under the Health Professions Act. The regulation allows the college to establish standards for professional practice, investigate complaints and police the use of the titles "naturopath" and "naturopathic doctor."

"Without that piece of regulation, there were potentially some public safety issues," says Allissa Gaul, a naturopathic doctor in Calgary, Alberta, who is the president of the new college. "A naturopathic doctor, as it is defined not just in Alberta but in any other regulated jurisdiction, is a very specific educa- tional process with a North Americanwide board examination. Without these regulations anybody could call themselves a naturopathic doctor, and there would be no legal recourse."

Alberta's 144 naturopathic doctors will now have regulations guiding how they provide injections, perform ear exams and conduct minor surgeries including suturing, collecting skin samples for biopsies and removing warts and moles. Once naturopathic doctors have obtained additional training, they can also perform acupuncture, chiropractic treatments and the intravenous administration of ozone, chelation therapy, vitamins and minerals.

Alberta joins British Columbia, Saskatchewan, Manitoba and Ontario in this formal regulation, although the legislative vehicles and scope of practice differ in each province. In British Columbia, for example, naturopathic doctors who complete a special certifi- cation course are allowed to prescribe drugs related to their practice, including some antibiotics and other primary care medication.

At one time, BC patients could also receive coverage under their provincial health plan for up to 10 consultations per year to naturopathic doctors. However, that changed in 2002 when the province lumped coverage together for all supplementary professions including physiotherapists, podiatrists, naturopathic doctors and chiropractors - funding only 10 visits per year for all those professions. Currently, no naturopathic doctors in $\mathrm{BC}$ bill the province because most first visits last 45 minutes to an hour, which the feefor-service model does not adequately compensate, says Glenn Cassie, executive director of the $\mathrm{BC}$ Naturopathic Association.

In Ontario, naturopathic doctors currently fall under the Naturopathy Act.

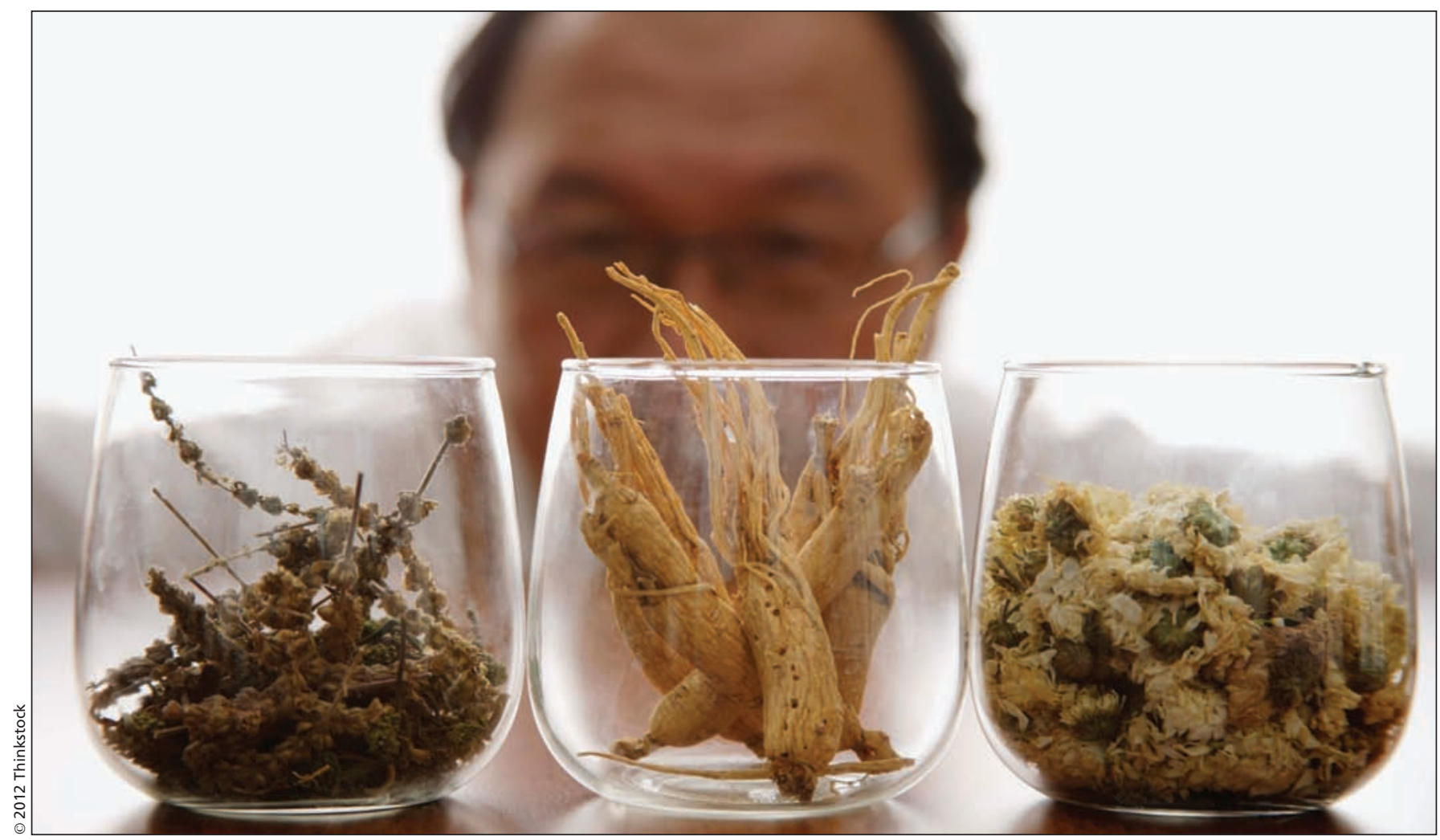

Government regulation of naturopaths is expected to lead to additional training requirements. 
By 2013, that act will become part of the umbrella Health Professions Act and will establish a new college of naturopaths, says Patricia Wales, vice-chair of the Canadian Association of Naturopathic Doctors. The national association is working with provincial associations in Ontario and Alberta to ensure that naturopathic doctors in those provinces will eventually share the prescribing powers of their colleagues in BC, Wales says.

"Prescribing rights are included in the national scope of practice that all provinces are striving towards meeting," she says.

In Saskatchewan, naturopathic doctors are regulated under the Naturopathy Act, which Wales describes as "antiquated." They are working with the provincial government to prepare bylaws to assist them in regulating current practice, she says. Manitoba has enacted umbrella legislation that covers all the health care professions, and naturopathic doctors will be in the sec- ond wave of professions moved under that legislation, she says. They will also be advocating for limited prescribing powers in Manitoba.

In other provinces and territories, the regulation of naturopathic doctors is at different stages. New Brunswick has prepared draft legislation to regulate naturopathic doctors, which other stakeholders are currently reviewing, says Wales. Nova Scotia's Naturopathic Doctors Act, passed in 2008, grants title protection and the ability for patients to claim visits or services as an income tax deduction. But it does not cover a naturopath's full scope of practice and doesn't allow effective regulation, says Wales.

The provincial association is currently discussing amendments to the legislation with the province.

Naturopathic doctors in Prince Edward Island have also approached their minister of health about regulation, says Wales. Naturopathic doctors are not regulated in Newfoundland and
Labrador, in the Yukon, or in Nunavut. In the Northwest Territories, an association of naturopathic doctors is working with legislators to have their profession included under proposed umbrella legislation for health professions.

In Quebec, naturopathic doctors fall under the Office of Professions, but do not operate under laws or regulations specific to their profession, which "restricts their practice immensely," says Wales.

Overall, says Wales, regulation is "a huge step forward for patients. They've been extremely supportive of us moving forward in this way and extremely glad to see it happen," she adds. "The more consistent we can be across the country, the better it is for patients to know what they can expect, and the better for naturopathic doctors to practise in different jurisdictions." - Laura Eggertson, Ottawa, Ont.

CMAJ 2012. DOI:10.1503/cmaj.109-4276 